\title{
Taste Fiber Responses during Reinnervation of Fungiform Papillae ${ }^{1}$
}

\author{
MARYLOU CHEAL, ${ }^{2}$ WILLIAM P. DICKEY, LEE B. JONES AND \\ BRUCE OAKLEY \\ Division of Biological Sciences, The University of Michigan, Ann Arbor, \\ Michigan 48109
}

\begin{abstract}
Crushing or transecting the chorda tympani nerve of the gerbil (Meriones unguiculatus) caused ipsilateral degeneration of taste buds in the fungiform papillae. In less than two weeks some taste fibers regenerated into the tongue and formed new taste buds and receptor cells. The recovery process was evaluated electrophysiologically in 53 gerbils by acute recording proximal to the nerve injury site. Initially the chorda tympani was electrically silent. In gerbils tested at later times spontaneous activity appeared. This was followed by responses to pressure on the tongue. Taste responses returned as early as day 11 . The receptive field of regenerated taste fibers was limited to a small number of fungiform papillae. Taste responses were always associated with the presence of one or more taste buds in the receptive field. Taste buds identified as responsive to chemicals contained some fusiform cells.

We found that the taste responses of single fiber, few-fiber and multi-unit preparations reflected the diversity of responses found in normal taste axons as determined by recording from 26 normal single fibers and 27 normal whole nerves. The early emergence of a variety of fiber types and responses to many chemicals in regeneration is inconsistent with the proposition that the relative chemical responsiveness of a receptor cell is strictly a function of its age; the response of a given young taste receptor is not necessarily limited to a few of the standard taste stimulants.
\end{abstract}

In electrophysiological studies of regeneration of sensory nerves the final state is usually evaluated without analysis of the process of recovery. An exception is a brief report by Brown and Iggo ('63) in which they examined the progressive return of functional properties of cutaneous touch receptors during regeneration of crushed or transected axons. The normal complement of mechanoreceptor types regenerated over a 10-day period (from 20 to 30 days post-operatively). Burgess and coworkers $(73,74)$ allowed one to three years for cutaneous nerve regeneration in cats. They found that the various functional types of mechanoreceptors were reestablished after nerve interruption and that the Merkel's domes tended to reappear in their normal locations. In the leech, Baylor and Nicholls ('68) found that a cutaneous sensory neuron will reestablish its characteristic functional responses after regeneration to the skin.

In an analysis of regeneration in the sense of taste, Oakley ('67) showed that integrated taste and temperature responses from 90 to 180-day regenerated rat chorda tympani nerves are indistinguishable from normal chorda tympani responses. In these experiments the chorda tympani was transected and the proximal stump sutured to its own distal stump or to that of the combined lingualchorda tympani nerve. In an analysis of the development of the sense of taste, Bradley and Mistretta ('73, '75) found presumptive

\footnotetext{
${ }^{1}$ Send reprint requests to: Bruce Oakley, Division of Bio logical Sciences, The University of Michigan, Ann Arbor Michigan 48109.

${ }^{2}$ Present address: Neuropsychology Laboratory, McLean Hospital, Belmont, Massachusetts 02178.
} 
taste buds and innervated fungiform papillae in tongues of fetal sheep as early as 50 days of gestation. The taste pores that admit chemical solutions from the oral cavity to the taste receptor cells were observed by 100 days of gestation. The authors recorded taste responses from single or few-fiber preparations of the chorda tympani nerve in fetuses aged 109 days to term (147 days) as well as integrated responses from the whole chorda tympani of fetuses, young lambs, and adult sheep. They concluded that the taste receptor system in the tongue was functional and morphologically mature at least during the last third of gestation.

There have been no investigations of functional responses from taste axons during the actual process of reinnervation of papillae and reformation of taste buds. Reinnervation is especially interesting in the sense of taste because the trophic dependence of taste buds upon neural innervation (denervated buds degenerate; reinnervated papillae form new buds) and the continuous turnover of taste bud cells indicate that dramatic changes in functional innervation must regularly occur in adult taste buds (e.g., Guth, '57; Beidler and Smallman, '65). Measurements of the timing and the physiological process of restoring taste responses are important not only in appraising how taste receptor cell systems are reestablished, but also in determining whether the functional characteristics of taste receptors are age dependent. It has been suggested that receptor cells may normally undergo a progressive age-related change in taste response profile (relative effectiveness of different chemicals) (Beidler and Smallman, '65). We proposed to test this hypothesis by recording at the earliest stages of regeneration when the majority of receptor cells would be young.

We examined the return of function in the chorda tympani nerve which innervates the fungiform taste buds on the anterior two thirds of the tongue. We chose the gerbil because we could interrupt the chorda tympani under the jaw near the chorda-lingual nerve junction and later readily record from more proximal undisturbed regions of the chorda tympani accessible in the middle ear.

In a companion study to the present investigation, Cheal and Oakley ('77) examined the innervation of the anterior two thirds of the gerbil tongue. Lingual nerve fibers innervate widespread regions of the tongue epithelium including the fungiform papillae; the chorda tympani in this area innervates only the fungiform papillae. All fungiform taste buds degenerate in the absence of the chorda tympani fibers, even when lingual fibers are present in the papillae. Cheal and Oakley removed the lingual nerve, crushed the chorda tympani and noted the regular time course and accurate return of fibers to the fungiform papillae. Taste buds were reformed within one to two days after reinnervation of the papillae. In the present report we examine electrophysiological responses associated with reinnervation of fungiform papillae. We wished to determine (a) when the new axonal outgrowths became responsive, (b) what types of taste responses were characteristic of newly formed receptor cells, (c) the location and size of the receptive field, and (d) the structural requisites essential for taste responses. It is generally assumed that there must be a substantial degree of organization within the taste buds if they are to initiate action potentials in the chorda tympani nerve during taste stimulation of the tongue. The taste solutions must have access through the taste pore in the keratinized layer of the epithelium to molecular receptors present within the membrane of differentiated taste receptor cells. In addition, there must be a synapse between the receptor cell and the sensory axon's terminals. Consequently, we examined the structure of taste buds which were physiologically identified as being the first to respond to taste stimulation. In this way we made some preliminary observations of the minimal structural requisites for a taste response. 
As a prelude to this experiment it was necessary to obtain responses from normal whole chorda tympani nerves and from normal single fibers as a basis of comparison with the regenerating system. We recorded integrated responses from 27 normal nerves with additional chemicals and concentrations beyond those already tested by Jakinovich and Oakley ('75). Inasmuch as there have been no previous studies of single taste fibers in gerbils we also recorded from 26 normal single taste fibers.

\section{METHODS}

Sixty-eight male and female Mongolian gerbils, Meriones unguiculatus, 3- to 7months-old, were used in this study. Experimental animals and breeding stock were obtained from a closed colony maintained by J. J. Hasenau of Northville, Michigan.

Operations to interrupt or to record from the chorda tympani nerve were carried out under sodium pentobarbital anesthesia. The animals, weighing between 35 and 60 gm, received an initial dose of $2.5 \mathrm{mg}$ i.p., followed by $2 \mathrm{mg} 15$ minutes later, with supplementary doses as needed. Each animal was secured with a headholder which immobilized the skull without the use of ear bars.

\section{A. General recording procedure}

A tracheal cannula was inserted to permit breathing during chemical stimulation of the tongue. The tongue was gently extended with a small hook inserted into the ventral epithelium contralateral to the site of recording. Solutions were flowed over the tongue by means of a gravity flow system. Test solutions, made with distilled water, were alternated with distilled water rinse of one minute or more without interruption of the fluid which flowed at a rate of about $0.2 \mathrm{ml} / \mathrm{sec}$. This eliminated transient mechanical stimulation of the tongue. The taste and rinse solutions were applied at a temperature of $23-26^{\circ} \mathrm{C}$, with minimal temperature variation among solutions during a given experiment. The following series of taste solutions was used, interspersed as indicated with a standard solution of $0.5 \mathrm{M}$ sucrose: $0.5 \mathrm{M}$ sucrose, $0.3 \mathrm{M}$ $\mathrm{NaCl}, 0.3 \mathrm{M} \mathrm{NH}_{4} \mathrm{Cl}, 0.3 \mathrm{M} \mathrm{KCl}, 0.05 \mathrm{M}$ acetic acid, $0.5 \mathrm{M}$ sucrose, $0.5 \mathrm{~m}$ fructose, $0.5 \mathrm{M}$ glycine, $0.02 \mathrm{M} \mathrm{Na}$ saccharin, $0.01 \mathrm{M}$ quinine hydrochloride, $0.5 \mathrm{M}$ sucrose, $0.05 \mathrm{M}$ citric acid, $0.5 \mathrm{M}$ dextrose (or $0.5 \mathrm{M} \alpha$-methyl-Dglucoside), Locke's Ringer's solution without dextrose, $2.0 \mathrm{~m}$ glycerol, and $0.5 \mathrm{M}$ sucrose. This series was used two or three times on each preparation. When responses were not obtained from regenerated nerves with these solutions, $1.0 \mathrm{M}$ and $2.0 \mathrm{M}$ sucrose, $1.0 \mathrm{M} \mathrm{NaCl}$, and $1.0 \mathrm{M} \mathrm{NH}_{4} \mathrm{Cl}$ were tested. Sucrose and $\mathrm{NaCl}$ concentration series were also used in several experiments.

We considered it possible that newly regenerated fibers might respond only to strong chemical stimulation. Consequently, in the initial experiments the following stronger chemical solutions were used: $0.05 \mathrm{M}$ quinine hydrochloride, $0.2 \mathrm{M}$ acetic acid, $0.2 \mathrm{M}$ citric acid, and $0.1 \mathrm{M} \mathrm{Na}$ saccharin. Once it became apparent that the thresholds were not extraordinarily high for most regenerated nerves, the weaker concentrations of these solutions noted above were used instead. Tap water at $15^{\circ} \mathrm{C}$ and $40^{\circ} \mathrm{C}$ and pressure applied to the tongue with a small glass rod were used for thermal and mechanical stimulation.

Multi-unit impulse activity was recorded on magnetic tape and integrated on-line (e.g., Grass Instrument Co. integrator). The integrated response gives a running average of much of the nerve's impulse activity which provides a useful assessment of the overall taste response characteristics. The peak magnitude of each integrated response was measured as a percentage of the response to the standard $0.5 \mathrm{M}$ sucrose solution.

Single or few-fiber spike activity in the first five seconds of the response was counted from taped data with a pulse height discriminator and window circuit. Photographic or storage oscilloscopic rec- 
ords were used to determine whether the spike originated from a single fiber, using the criteria of constancy of spike height and absence of coincident spikes.

\section{B. Neural activity from the regenerated chorda tympani nerve}

The chorda tympani of 53 gerbils was unilaterally interrupted under the jaw by crushing or transecting as described by Cheal and Oakley ('77). As detailed in the results section, in 33 of the experimental animals various other tongue nerves were transected as control procedures (table 1). Each animal received 5,000 units of penicillin i.m. and was allowed to recover for one to three weeks. Since the earliest stages of functional recovery occurred during the second week, most recordings were made during that time period.

Spontaneous and elicited action potentials were recorded from the whole chorda tympani nerve as it passed through the middle ear on its route to the brain as previously described by Jakinovich and Oakley ('75). Thus, it was possible to record from the undisturbed chorda tympani where it spanned an air gap within the middle ear simply by touching the whole nerve with a $120 \mu \mathrm{m}$ diameter nichrome wire electrode.

\section{Regenerated multi-unit responses}

Integrated taste responses were obtained 11 to 20 days after interruption of the chorda tympani nerve. Records involving responses from only a few fibers were not integrated.

\section{Regenerated single and few-fiber responses}

We observed during the early phases of recovery that responses could be isolated from one or a few taste fibers while recording from the whole chorda tympani nerve in the middle ear. In these instances small spikes were often present. In four nerves single fiber records were obtained as defined by non-coincident spikes, constant spike height and a restricted receptive field on the tongue. In 16 other nerves, records were obtained from one or a few fibers. We call these "few-fiber" responses. All single and few-fiber records were obtained from whole chorda tympani nerves. We did not attempt to split the chorda tympani into fine bundles for single fiber recording.

\section{Responses of the normal chorda tympani nerve}

\section{Multi-unit activity}

Integrated responses from 27 whole chorda tympani nerves were recorded. Twenty of the 27 records were obtained from the intact chorda tympani contralateral to the interrupted chorda tympani.

\section{Normal single fiber responses}

To obtain responses from normal single units, the chorda tympani was exposed under the jaw and transected at its distal exit from the tympanic bulla. Fine steel needles were then used to subdivide the nerve into small bundles which were successively lifted onto a nichrome wire electrode for conventional AC amplification and oscilloscopic display of action potential activity. Twenty-six single taste fibers from 11 gerbils were identified functionally by stimulating the tongue with a taste mixture consisting of $0.3 \mathrm{M} \mathrm{NaCl}, 0.1 \mathrm{M}$ quinine hydrochloride, $0.05 \mathrm{M}$ citric acid and $0.5 \mathrm{M}$ sucrose.

\section{Histological procedure}

From an anatomical study of regeneration (Cheal and Oakley, '77) it was known that by the time the first electrophysiological responses could be elicited some fungiform papillae had been reinnervated and some taste buds reformed. The anatomical interest in the present experiment was to make an initial morphological examination of newly reformed taste buds which lay in a taste fiber's receptive field. Thus, when possible, the receptive field of a single fiber was mapped and the location of the responsive papilla indicated by measurements or by deposition of ferric ions in nearby tissue for a Prussian blue staining 
reaction. The gerbils were perfused with a mixture of $4 \%$ formaldehyde and $15 \%$ sucrose and the tongues embedded in paraffin. Ten micron serial cross-sections were cut and stained with Heidenhain's iron hematoxylin to visualize the taste buds. The position of fungiform taste buds and the fiber's physiological receptive field were reconstructed on an outline diagram of the tongue.

\section{RESULTS}

\section{A. Surgical controls}

Control nerve transections were carried out to ensure that the regenerating chorda tympani fibers did not reinnervate existing taste buds maintained by other nerves. The most probable site for innervation of existing taste buds would have been the foliate papillae where most buds are innervated by the IXth nerve and a few by the chorda tympani in gerbils. The vallate papilla and the contralateral fungiform papillae are also sources of existing taste buds to which regenerating chorda fibers might return. To prevent the interrupted chorda tympani from innervating existing taste buds, we transected various other tongue sensory nerves in 33 of 53 experimental gerbils from which electrophysiological records were obtained (table 1). Response properties in these animals did not differ from responses in those which had undergone only crushing of the chorda tympani. Further, Cheal and Oakley ('77) have shown that (a) normal chorda tympani fibers are not found in contralateral locations, (b) in four weeks neither normal nor regenerated chorda tympani fibers grow to contralateral locations, and (c) that the lingual and XIIth nerves will not sustain fungiform taste buds. From the above control observations we conclude that the taste responses of regenerating chorda tympani fibers did not result from reinnervation of existing taste buds maintained by other tongue sensory or motor nerves.

\section{B. General characteristics of the neural responses}

No impulse activity could be detected while recording from the chorda tympani nerve in the ear of four animals one-half to one hour after crushing the chorda tympani under the jaw. Furthermore, in most animals, at early recovery times (7-10 days) the nerve was silent. (Viable efferent fibers may have been present, but their spontaneous discharge would have been blocked by the barbiturate anesthetic [Hellekant, '71]). Therefore, the crushing procedure functionally interrupted the axons. Taste responses were obtained from zero of four 7- to 10-day, two of four 11day, and six of seven 12-day animals.

The time course of functional recovery of the interrupted chorda tympani nerve is shown in figure 1. The data show the average number of days required to reach a given stage of functional recovery follow-

TABLE 1

Nerve operations ipsilateral and contralateral to the crushed or transected chorda tympani nerve from which recordings were made

\begin{tabular}{|c|c|c|c|c|c|c|c|}
\hline \multicolumn{3}{|c|}{ Ipsilateral nerves } & \multicolumn{3}{|c|}{ Contralateral nerves } & \multirow[b]{2}{*}{$\mathbf{N}$} & \multirow{2}{*}{$\begin{array}{l}\text { Number of days } \\
\text { postoperative }\end{array}$} \\
\hline C.T. (record) & IX & $\mathbf{L}$ & C.T. & IX & $\mathrm{L}$ & & \\
\hline $\begin{array}{l}\text { Crush } \\
\text { Crush } \\
\text { (x) } \\
\text { Crush } \\
\text { Crush } \\
\text { Crush } \\
\text { (x) }\end{array}$ & $\begin{array}{l}(\mathbf{x}) \\
(\mathbf{x}) \\
(\mathbf{x}) \\
(\mathbf{x}) \\
(\mathbf{x})\end{array}$ & $(\mathbf{x})$ & $(\mathbf{x})$ & $\begin{array}{l}(\mathrm{x}) \\
(\mathrm{x})\end{array}$ & & $\begin{array}{r}20 \\
8 \\
10 \\
6 \\
3 \\
3 \\
3\end{array}$ & $\begin{array}{r}8-19 \\
12-14 \\
14-16 \\
13-16 \\
11-13 \\
12-14 \\
13.15\end{array}$ \\
\hline & & & & & & $E=5$ & \\
\hline
\end{tabular}

(x) Indicates nerve transection. The range of days allowed for postoperative recovery is indicated. C.T., chorda tympani nerve; IX, glossopharyngeal nerve; L, lingual nerve proper. 


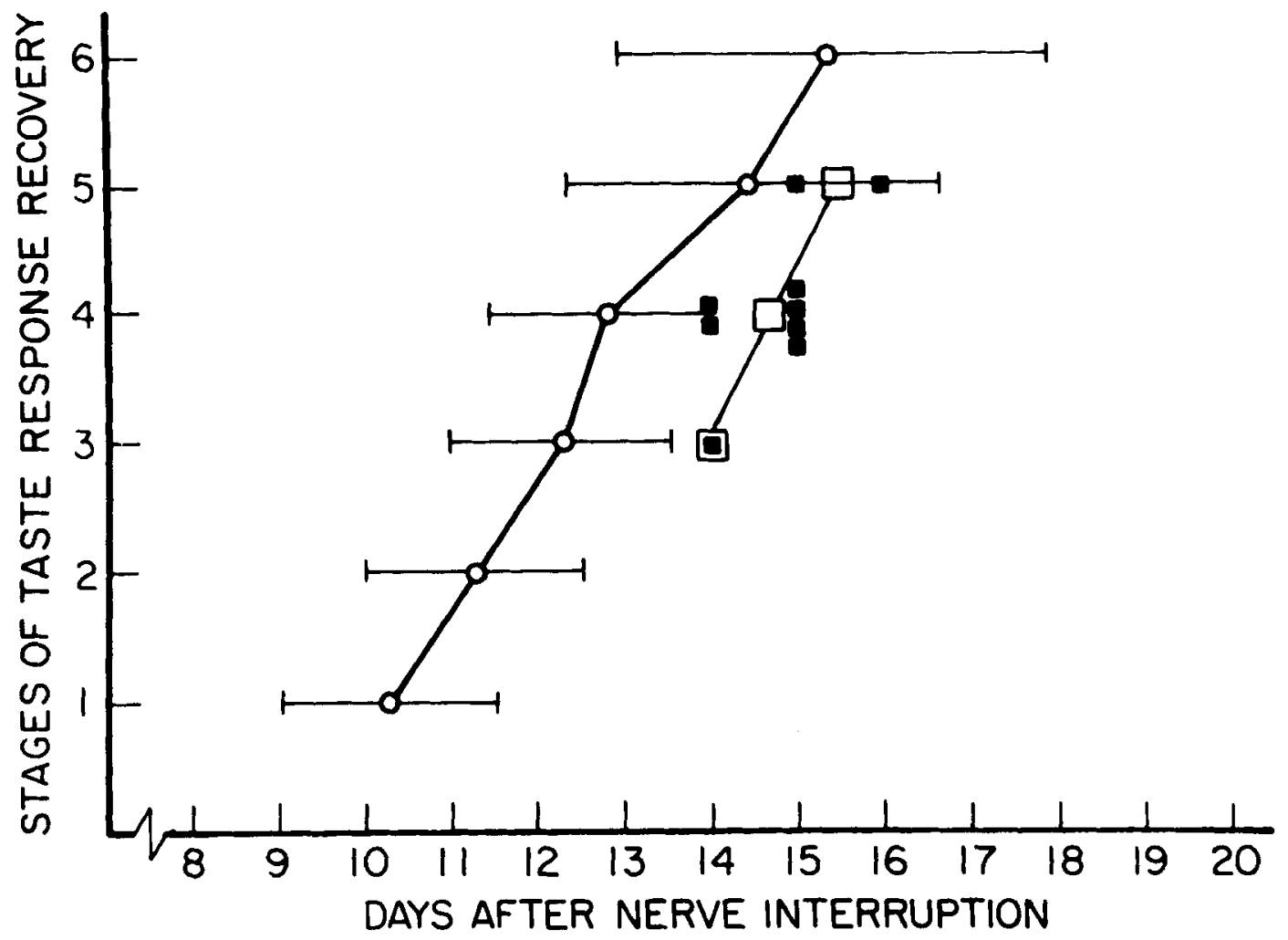

Fig. 1 Mean number of days required to reach a given stage of functional recovery. Ordinate: stages of recovery of chorda tympani neural activity. Stage 1, spontaneous activity only. Stage 2 , impulse discharge to pressure on the tongue - no other sensory stimulation effective. Stage 3, one or two responsive taste fibers. Stage 4, a few responsive taste fibers (e.g., 3-6). Stage 5, multi-fiber discharge. Stage 6, multi-fiber discharge with an integrated taste response similar to normal. Abcissa: number of days after chorda tympani crush, $N=21$, (open circles, means; bars, standard deviation) and after chorda tympani transection, $N=9$ (open squares, means; filled squares, individual animals).

ing crushing (circles, $\mathrm{n}=21$ ) or cutting of the nerve (squares, $n=9$ ). Recovery of function was classified into six stages of progressive improvement. In stage 1, spontaneous impulse discharges were present, but neither mechanical, thermal, nor chemical stimulation was effective in eliciting discharges. In stage 2, pressure to the tongue initiated action potentials. However, inasmuch as light touch or light pressure were generally ineffective it may be that axons were being unphysiologically stimulated. In crushed nerves the first one or two taste fibers (stage 3 ) responded at a mean recovery time of 12.3 days, 11 days being the earliest. The regenerating taste fibers had the following normal properties by stage 3 of recovery: (a) spontaneous activity, (b) a response to taste solutions with an irregular discharge followed by partial adaptation, (c) an increase in firing rate with chemical concentration, and (d) both broad (many effective chemicals) and narrow response profiles. The population of regenerating fibers responded to all of the chemicals tested. By stage 4 , three to six taste fibers were responsive. Some spikes were small, but impulses from the larger ones could be counted reliably. After a mean of 14.4 days following nerve crush, the chorda tympani had many active taste fibers whose responses could be integrated (stage 5). In stage 6 the integrated multifiber discharge was similar to the inte- 

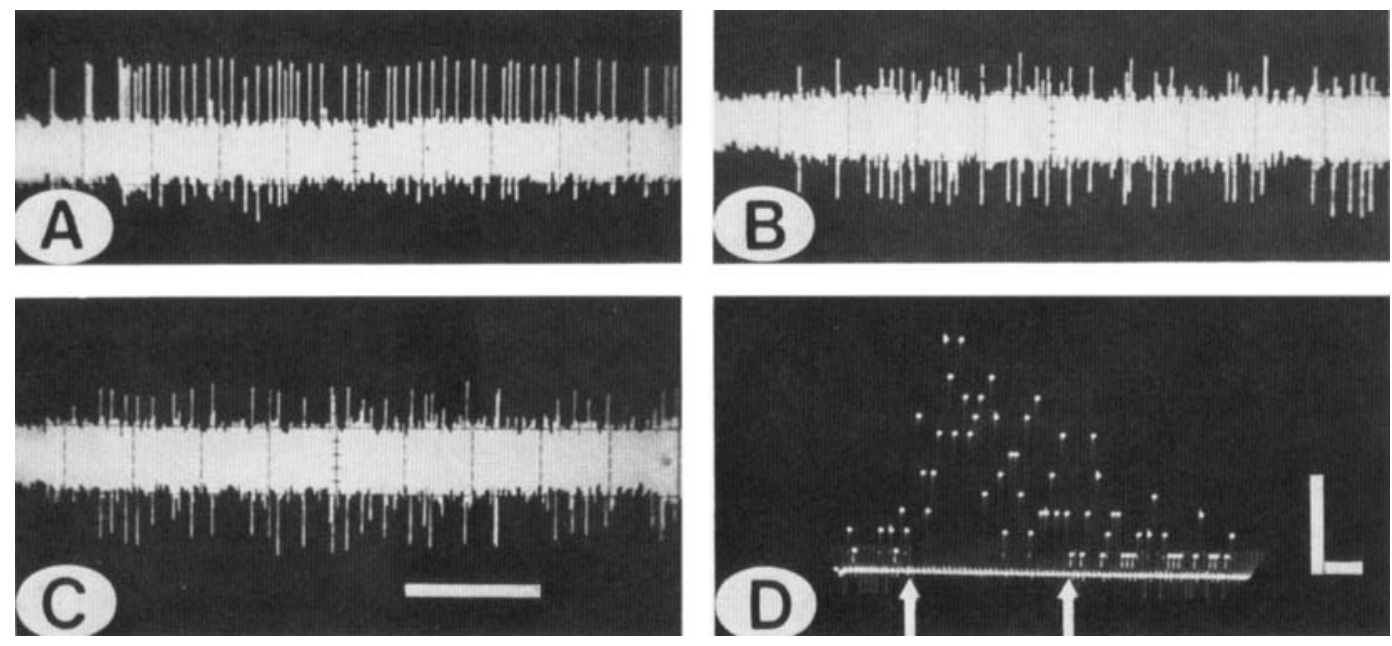

Fig. 2 Regenerated chorda tympani nerve responses recorded 11 to 12 days after nerve crush. $A$. Discharge of a single fiber in gerbil 35 (stage 3,11 days) to $1.0 \mathrm{M} \mathrm{NH}{ }_{4} \mathrm{Cl}$ applied with a paint brush to a responsive papilla near the tip of the tongue. A branch of the same axon also innervated a papilla 6 $\mathrm{mm}$ more posterior. B. Response of a few fibers in gerbil 56 (stage 5,12 days) to $0.05 \mathrm{M}$ citric acid flowing over the tongue. C. Response of a few fibers in gerbil 55 to $0.1 \mathrm{M}$ sucrose flowing over the tongue. Time line for $\mathrm{A}, \mathrm{B}, \mathrm{C}, \mathbf{=}=\mathbf{0 . 4}$ seconds. D. Post stimulus time histogram. Response in gerbil 55 to $0.05 \mathrm{M}$ sucrose flowing over the tongue followed by a distilled water rinse. Vertical bar, 5 impulses; horizontal bar, 10 seconds. Bin width of counter $=500$ milliseconds.

grated records from the normal nerve in terms of the relative effectiveness of different chemicals (response profile). Cutting the chorda tympani delayed the stages of recovery by about two days (squares in fig. $1, N=9$ ).

A pulse height discriminator and window circuit were used to record single fiber responses at stage $3(N=3)$ and $4(N=1)$, and few-fiber responses at stage $4(\mathrm{~N}=9)$, $5(N=5)$, and $6(N=2)$. Spike counts permitted a more exact analysis than would have been possible with integrated responses alone (see examples of spike data in fig. 2). The single fiber in figure $2 \mathrm{~A}$ responded predominantly to $\mathrm{NH}_{4} \mathrm{Cl}$ at day 11. Its spike could be elicited by chemical stimulation restricted to either of two widely separated receptive sub-regions on the tongue. Stimulation elsewhere was ineffective. In figures $2 \mathrm{~B}$ and $2 \mathrm{C}$ few-fiber responses are presented for citric acid and sucrose, respectively. The post-stimulus time histogram to $0.05 \mathrm{M}$ sucrose of the largest spike of gerbil 56 indicates that relatively weak stimuli could be effective (fig.
2D). The longer time period of this record also shows a slowly rising transient followed by adaptation to a lower level of activity. When the distilled water rinse was applied, the response declined to the resting level. Rhythmic bursting was sometimes evident in responses to sucrose. This was also observed with normal taste fibers.

\section{Composite taste response profiles}

The data from regenerated fibers had to be processed by two different methods. In the recordings during the early stages of regeneration spikes from one or a few fibers were counted. With multi-unit responses after longer regeneration times (stages 5,6 ) it was commonly impossible to count even the largest spikes. Therefore, an integrator method of analysis was carried out. For comparison, responses of normal chorda tympani nerves were obtained consisting of multi-unit responses averaged with an integrator circuit and single unit data counted with a discriminator and window circuit. 

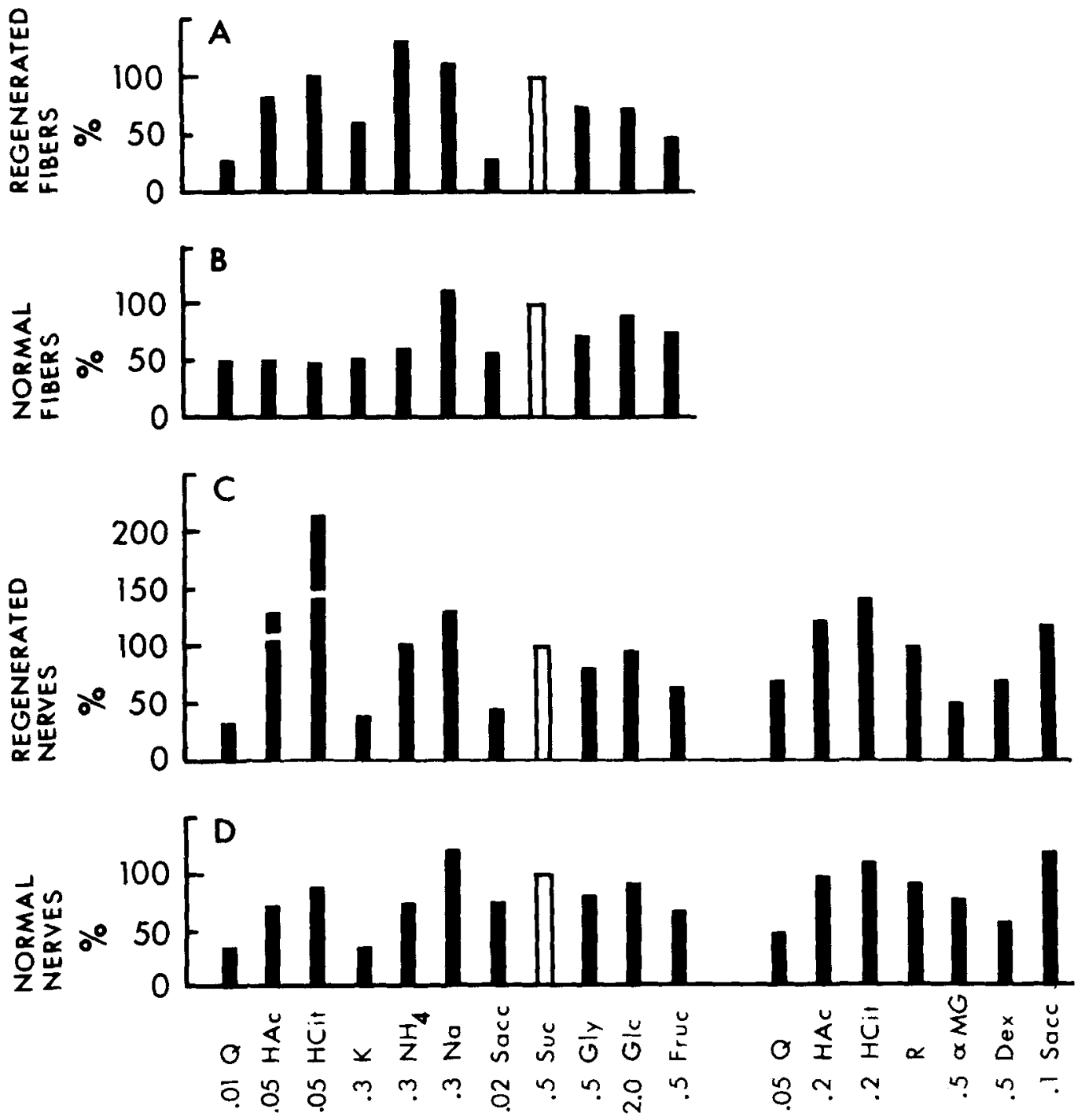

Fig. 3 Taste response profiles: Group data. A. Composite response profile of $2011-$ to 16 -day $(\overline{\mathrm{x}}$ $=13.6$ day) regenerated chorda tympani nerves, each contained one or a few functional taste fibers. Ordinate: the response measure was the number of impulses/second in the first five seconds of the response. For each chemical the responses (mean impulses/sec in first 5 seconds) were averaged across all 20 preparations. The mean spike discharges are presented as a percentage of the mean response to sucrose. Abcissa: molar concentrations of quinine, acetic acid, citric acid, $\mathrm{KCl}, \mathrm{NH}_{4} \mathrm{Cl}, \mathrm{NaCl}, \mathrm{Na}$ saccharin, sucrose, glycine, glycerol, and fructose. B. Composite response profile of 26 normal single fibers dissected from the chorda tympani nerve. Ordinate and chemicals as in A. C. Mean integrated responses from 11 - to 20 -day $(\overline{\mathrm{x}}=15.5$-day) regenerated chorda tympani nerves. For each nerve the responses were computed as a percentage of the response to sucrose. Group means of these percentages are presented. Nine of 15 regenerated nerves in $C$ and 11 of 27 normal nerves in D were tested with $0.05 \mathrm{M}$ quinine hydrochloride, $0.2 \mathrm{M}$ acetic acid, $0.2 \mathrm{M}$ citric acid, $0.1 \mathrm{M} \mathrm{Na}$ saccharin, and $0.5 \mathrm{M} \alpha$ methyl-D-glucoside. The other nerves were tested with $0.01 \mathrm{M}$ quinine hydrochloride, $0.05 \mathrm{M}$ acetic acid, $0.05 \mathrm{M}$ citric acid, $0.02 \mathrm{M} \mathrm{Na}$ saccharin and $0.5 \mathrm{M}$ dextrose. The remaining chemicals including Ringer's $(\mathbf{R})$ were used with all nerves. Animals represented in A were excluded from the integrated analysis of $\mathrm{C}$. The break in the response bars for the weaker solutions of the two acids indicates the mean response in the absence of one gerbil with a large acid response. D. Mean integrated response from 27 normal chorda tympani nerves. Stimuli and computation as noted in $C$. 
Before the analysis of the taste responses is taken to the level of single fibers it would be appropriate to consider a summary of all of the response profile data in the form of four composite taste response profiles: integrated discharges from normal nerves, integrated discharges from regenerated nerves, normal single unit discharges and regenerated single and few-fiber discharges (fig. 3). (Individual response profiles of single or few-fiber responses will be presented in figs. 4-6.)

The integrated responses were computed for each animal as a percentage of the responses to sucrose. Mean percentages were then calculated. The single and few-fiber data could not be treated in this way because some normal and regenerated fibers had such low responses to sucrose that enormous percentage responses to other chemicals resulted. Consequently, for each chemical, the impulse counts were averaged for all fibers and then expressed as a percentage of the mean discharge to sucrose. (Operationally, this is equivalent to recording simultaneously from many gerbils, each with a single or a few-functional regenerated taste fibers.) The response profiles of single or few-fiber discharges from 20 regenerated nerves have been averaged in figure $3 \mathrm{~A}$. The mean age of recovery was 13.6 days. It is immediately apparent from this representation that all tested chemicals were effective. The four basic tastes, bitter, sour, salt, and sweet, were represented in the sample of chemicals. The most effective chemical was $\mathrm{NH}_{4} \mathrm{Cl}$. Figure 3B displays the group data from 26 normal single fibers. Composite response profiles of integrated multi-unit discharges are shown for 15 other regenerated nerves not represented in figure 3A (fig. 3C) and for 27 normal chorda tympani nerves (fig. 3D). Allowing for the possibility that the regenerating fibers might fail to respond to moderate concentrations, in the initial phase of the study all regenerated nerves were tested with stronger solutions. That data is included at the right of figures $3 C$ and $3 D$. In regenerated fibers the response to acids was sometimes large. The mean responses to $0.05 \mathrm{M}$ acetic and $0.05 \mathrm{~m}$ citric acids in figure $3 \mathrm{C}$ were large owing to the response of one nerve. The break in the bars is the mean response without that nerve. It is unclear why the normal single fibers had a weak acid response, since it was relatively larger in the integrated responses of normal nerves. One statistically significant difference between normal and regenerated fibers existed. $\mathrm{NH}_{4} \mathrm{Cl}$ was a better stimulus than $\mathrm{NaCl}$ in a higher proportion of regenerated $(53 \%)$ than normal $(28 \%)$ fibers $(p<0.03$, Chi Square test). Furthermore the mean days of recovery in those fibers with $\mathrm{NH}_{4}>\mathrm{Na}$ was 12.9 days, vs. 14.1 days for fibers in which $\mathrm{Na}>\mathrm{NH}_{4}$. At later times in recovery $\mathrm{NH}_{4} \mathrm{Cl}$ was generally less effective than $\mathrm{NaCl}$. Compare figures $3 \mathrm{~A}$ (13.6 days) and 3C (15.5 days).

Notwithstanding this difference, the overall conclusion in this comparison of composite data from 35 regenerated and 38 normal nerves is that the regenerating fibers had a composite response profile remarkably similar to the normal response profile based upon single fiber and integrated whole nerve responses. This is further substantiated by the analysis of single and few-unit responses from individual animals.

\section{Single and few-fiber response profiles of the regenerated chorda tympani nerve}

\section{Single fiber response profiles}

Four of the regenerated nerves that gave a single fiber record were tested with the full set of taste chemicals (fig. 4). Unit 35 which responded primarily to $\mathrm{NH}_{4} \mathrm{Cl}$, was one of the earliest ( 11 days) to respond to taste solutions. Units 103 and 70 responded to sucrose at 13 and 15 days respectively. Unit 63 (14 days) responded best to $\mathrm{NaCl}$ with lesser responses to $\mathrm{NH}_{4} \mathrm{Cl}, \mathrm{KCl}$, and the acids. The spontaneous activity (dotted bar) is shown for each unit. These records indicate that a variety of chemicals could activate newly regenerated taste fibers with varying effectiveness.

\section{Few-fiber response profiles}

Few-fiber taste responses were recorded 


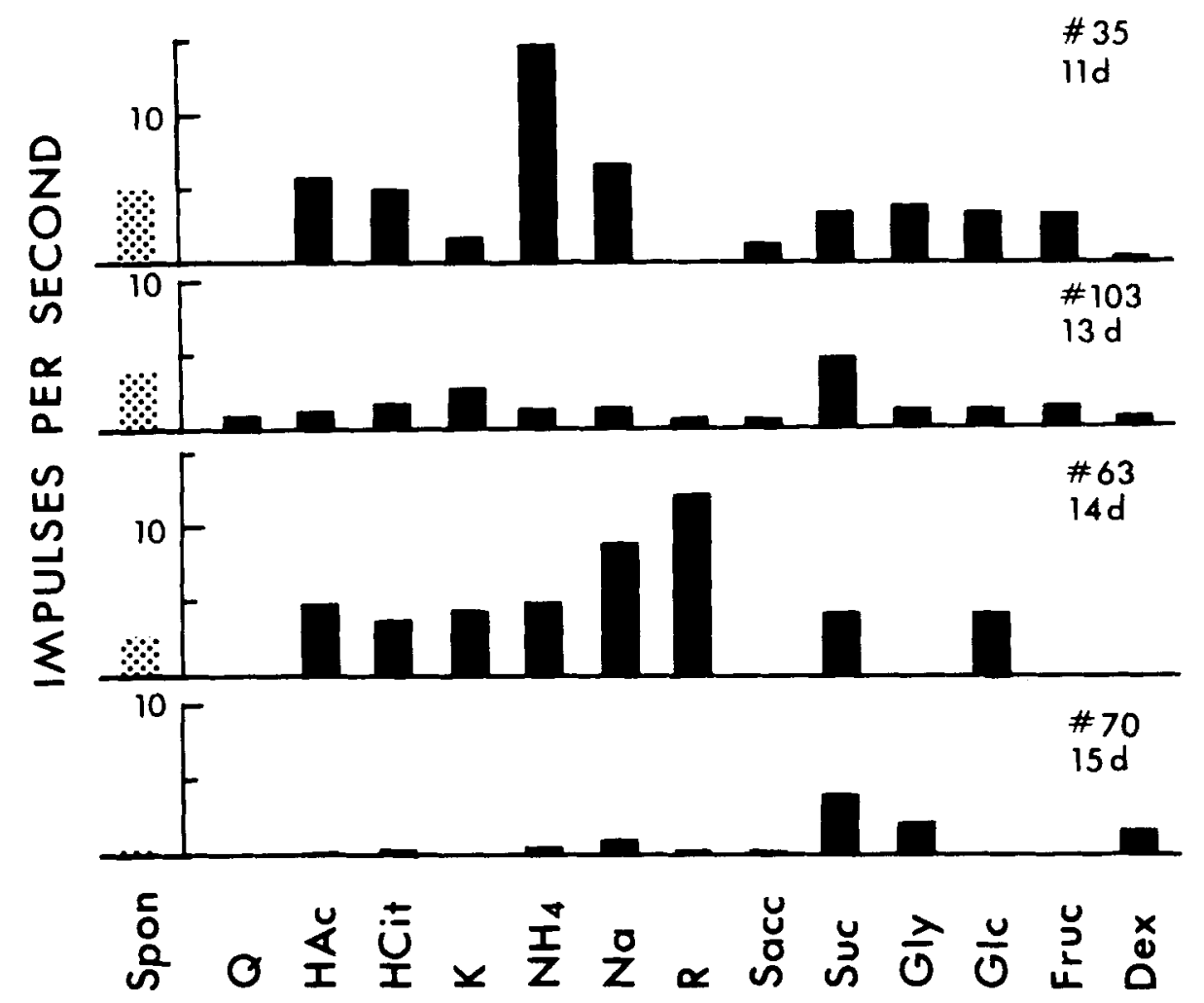

Fig. 4 Taste response profiles of regenerated single fibers of the chorda tympani nerve. The spontaneous level of activity with distilled water flowing over the tongue is indicated by the dotted bar on the left for each of the four units. The responses shown are the impulses/second in the first 5 seconds of the response minus the mean spontaneous activity. The days since nerve interruption are indicated. The chemicals and concentrations are the same as in the left of figure 3 plus Ringer's, and $0.5 \mathrm{M}$ dextrose. Stage $3(35,63$, and 103); stage $4(70)$. The chorda tympani was crushed in gerbils 35,63 , and 103 , and transected in 70 .

from 16 regenerated nerves. A representative sample of the 16 response profiles is presented in figure 5 . Although gerbils 55 and 56 both had 12-day regenerated chorda tympani nerves, the response profiles were quite different. 55 responded primarily to sugars, whereas 56 responded to acids with little response to sugars. Since vigorous responses to quinine are normally rare, the emergence of this quality could not be assessed except to note that good responses to quinine sometimes did occur (92).

Ninety-two had vigorous responses to most chemicals (note the ordinate). This nerve highlights an important limitation of few-fiber preparations. Namely, that it was impossible to prove that individual fibers had broad response profiles. 92 might have been, and probably was, a composite of profiles of several single fibers. Alternatively, evidence for specificity, when it occurred, is valid. For example, 68 (a 15day regenerated nerve like 92) responded selectively to acid.

Among these 16 profiles, not only was the rapid maturation of specificity demonstrable in terms of the four basic taste qualities, but it was also demonstrable within a basic quality. Note the acid responses of 74, 95, and 77. In two cases only citric acid was effective; in the other acetic was more effective than citric acid. Thus, differential responsiveness to the 


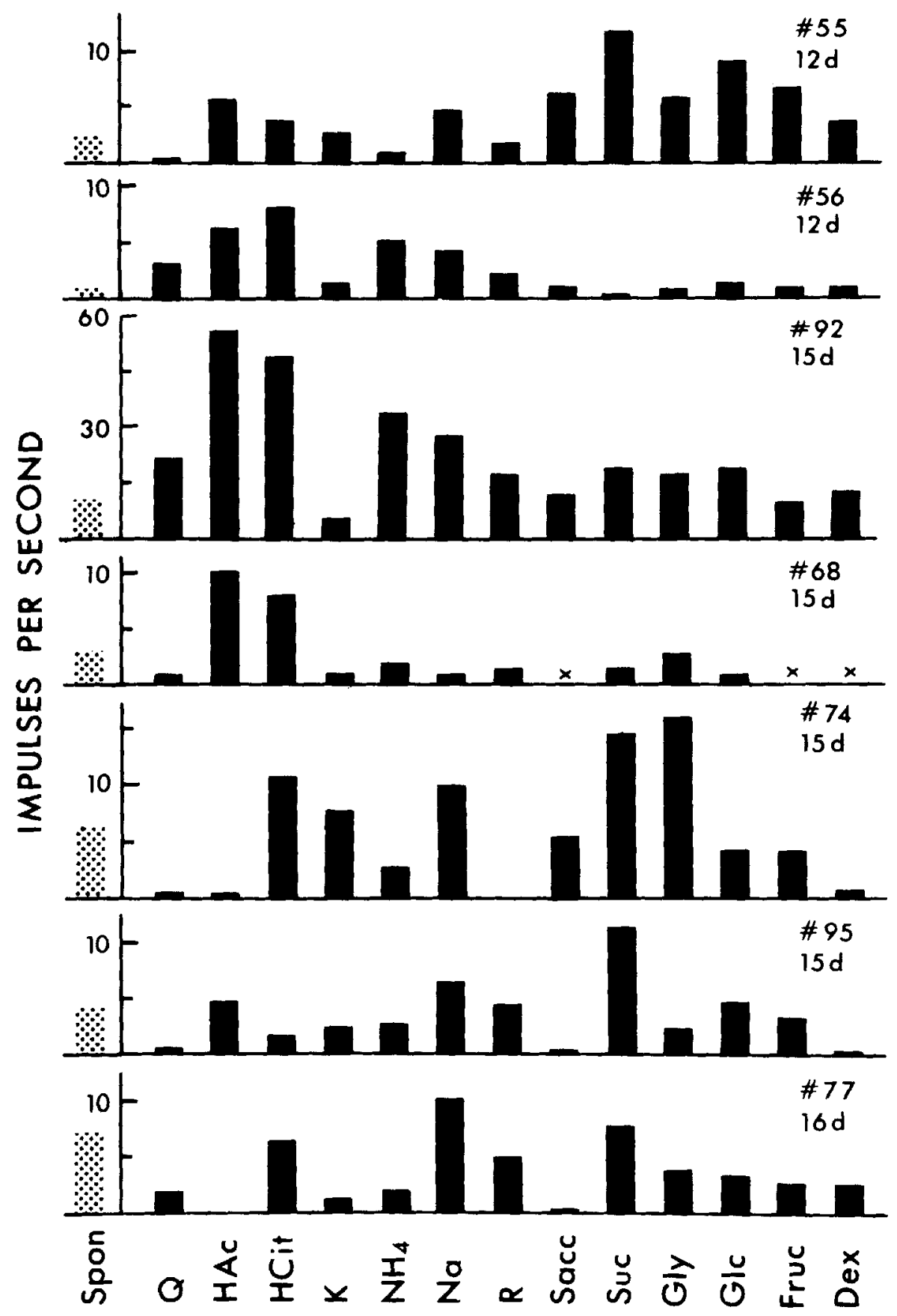

Fig. 5 Few-fiber response profiles of seven representative regenerated chorda tympani nerves. Stimulants not tested are indicated by " $x$ ". Stage $4(68,74$, and 95$)$, stage $5(55,56$, and 77$)$, stage 6 (92). The chorda tympani was crushed in gerbils $55,56,92$, and 95 , and transected in 68,74 , and 77 . Other details as in figure 4. 


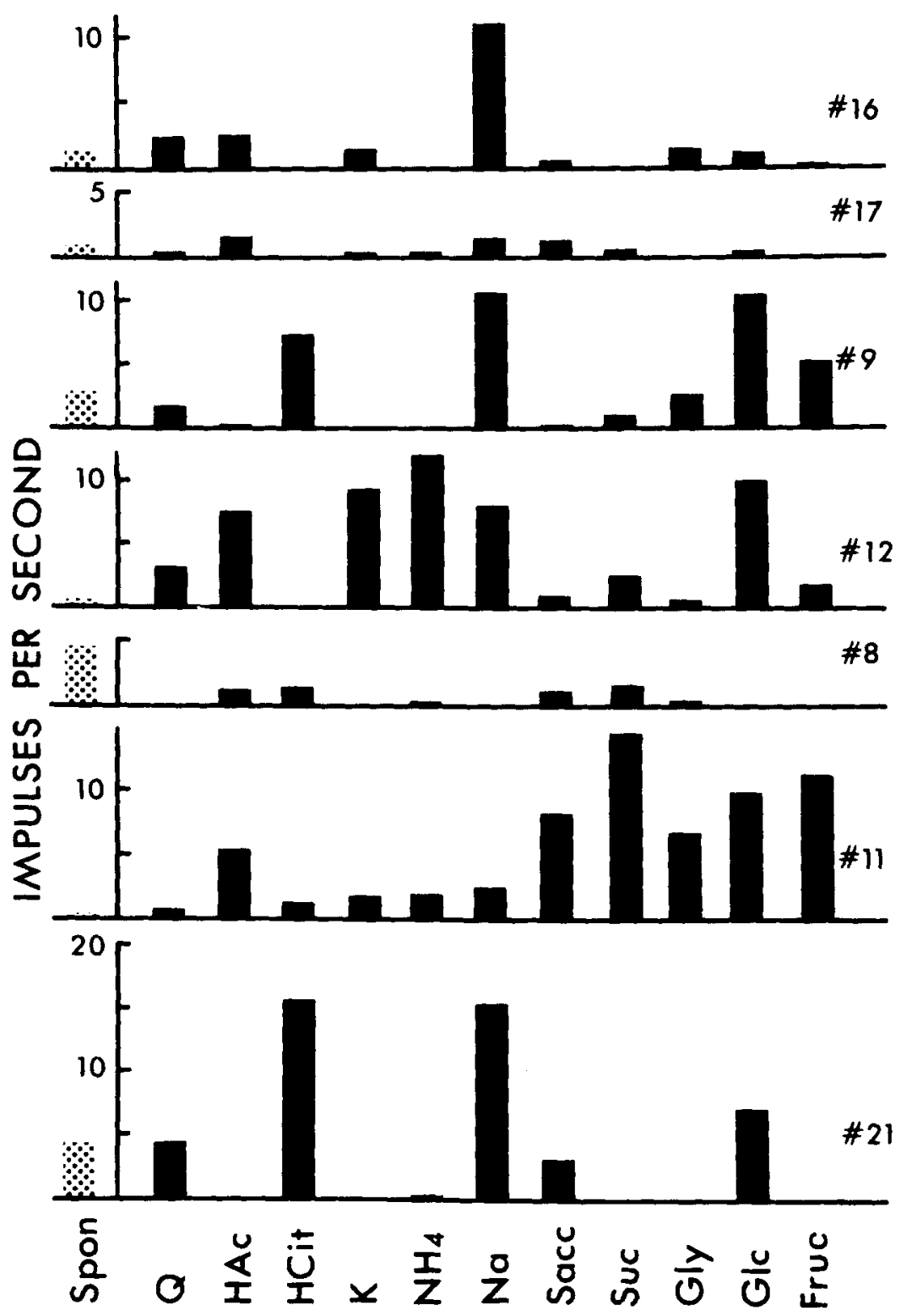

Fig. 6 Response profiles of a random sample of seven of 26 normal single fibers. Other details as in figure 4.

anion of an acid was also rapidly reestablished in the regenerating taste receptor system. The acids were not acting as indiscriminate irritants. Similarly, among compounds sweet to humans, differential responses were apparent. Compare, for example, the relative effectiveness of sucrose and glycine (Gly) for nerves 74 and 95. There were two or more few-fiber preparations displaying each of the response properties noted here.

The responses of most regenerated single and few-fiber preparations were reproducible. Thresholds did not appear to 


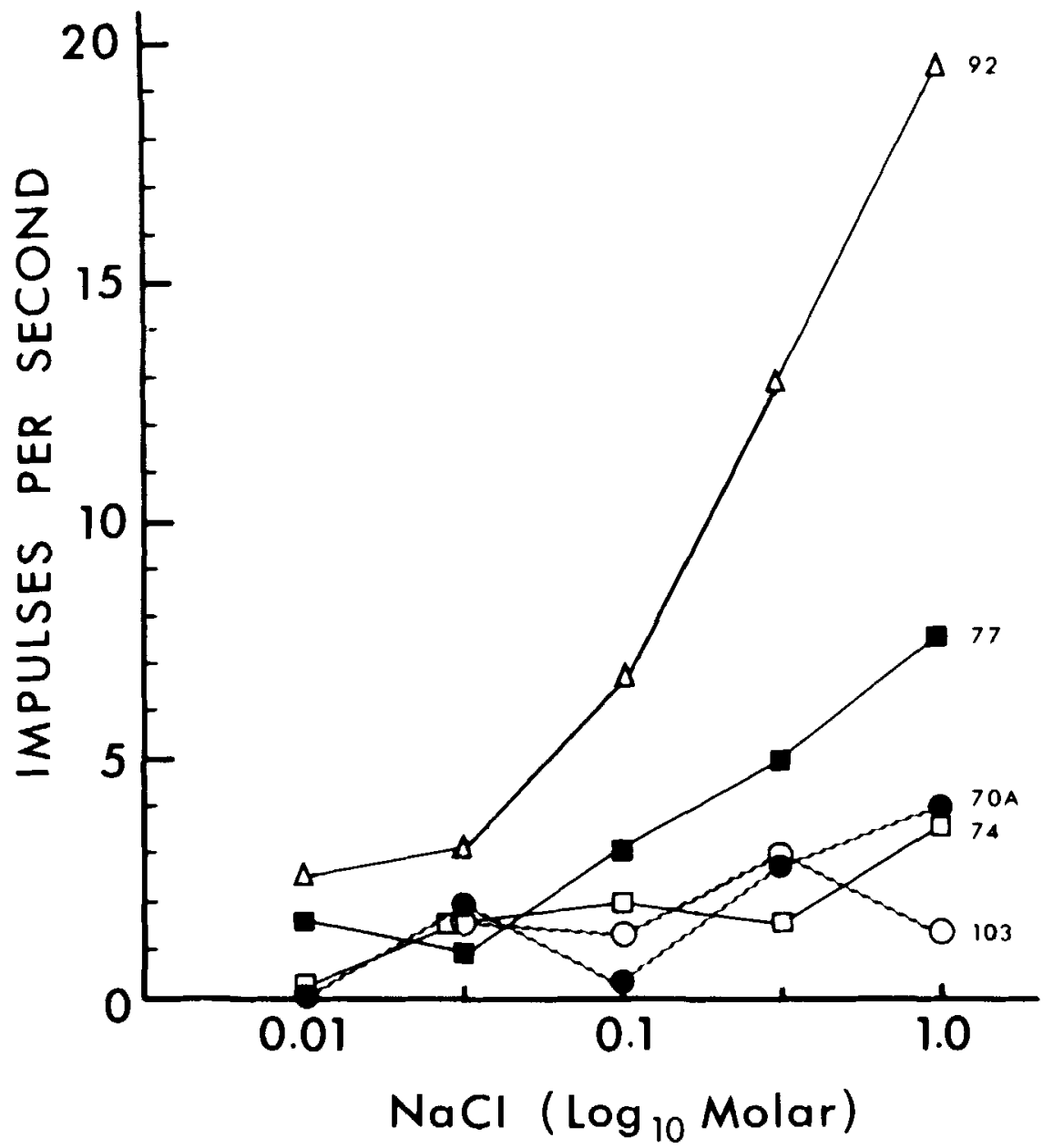

Fig. $7 \mathrm{NaCl}$ concentration-response functions for regenerated single fiber (wavy lines) or fewfiber preparations (solid lines). Ordinate: impulses/second in the first five seconds of the response. The stage and age of regeneration are as follows: 70 and 74 , stage 4,15 days; 77 , stage 5,16 days; 92 , stage 6,15 days, and 103, stage 3,13 days. The chorda tympani was crushed in gerbils 92 and 103, and transected in 70,74, and 77. A window circuit was used to discriminate fiber $70 \mathrm{~A}$ from the larger spike of fiber 70 .

be abnormally high. It was unnecessary to use the stronger solutions, because the set of moderately intense chemical solutions was typically effective. However, there were a few nerves in which only intense solutions (e.g., $1.0 \mathrm{M} \mathrm{NaCl}, 1.0 \mathrm{M} \mathrm{NH} \mathrm{N}_{4} \mathrm{Cl}, 2.0$ $\mathrm{M}$ sucrose and $0.2 \mathrm{M}$ acetic acid) would produce a response.

A quantitative statement about fiber types cannot be made, because as discussed earlier a given profile may reflect the composite responses of more than one fiber.
However, it is qualitatively apparent that there is a diversity of fiber types. For example, 68 was selectively responsive to acids. Among the four single units (fig. 4) 35 was selectively responsive to $\mathrm{NH}_{4} \mathrm{Cl}, 70$ and 103 to sucrose and 63 to acids and $\mathrm{Na}$ (Ringer's). As soon as the first taste responses could be recorded (11-12 days) differential sensitivity to salts, acids, and sugars was present. The range of selective responses, the diversity of the few-fiber response profiles, and underlying it the 


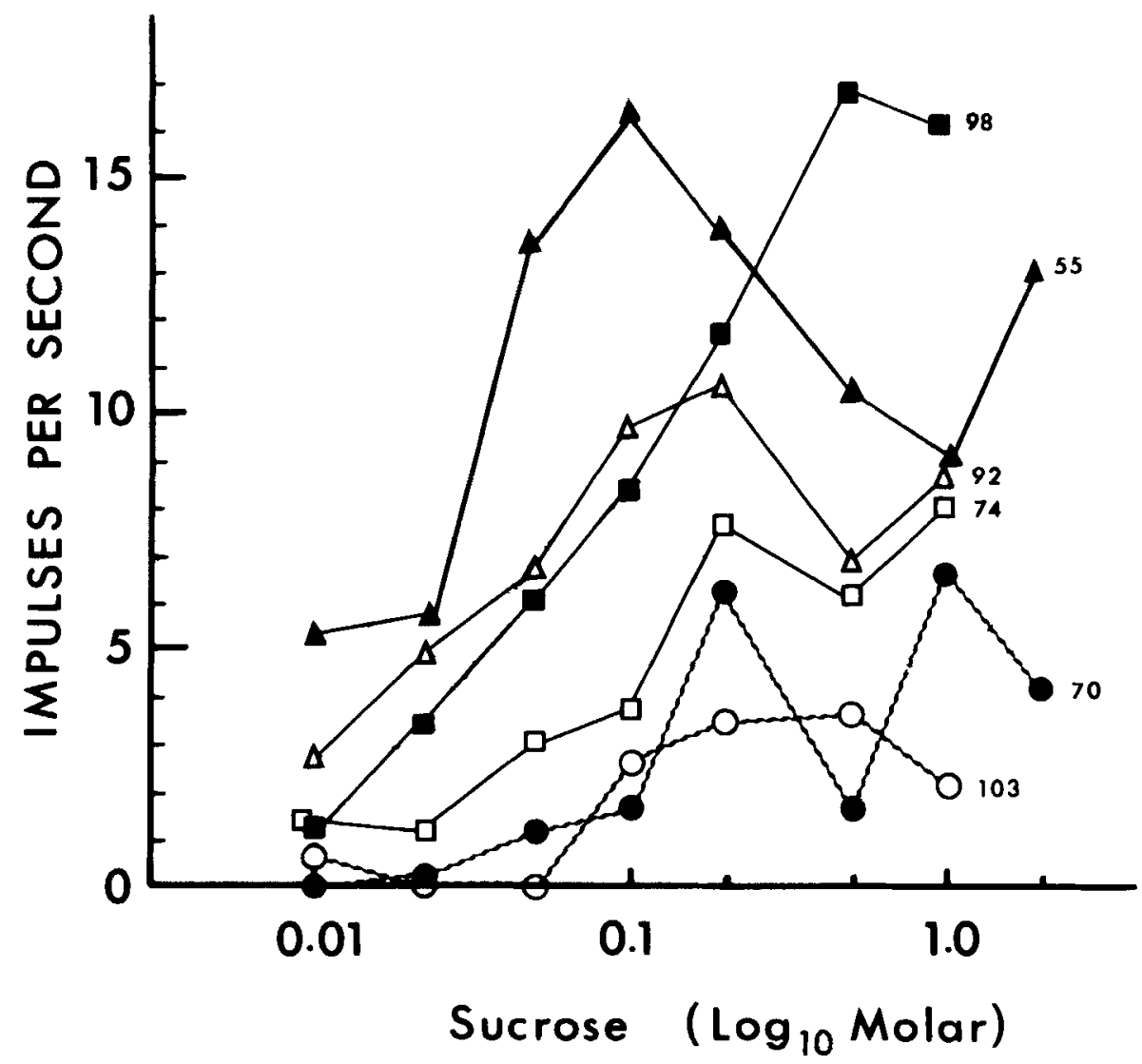

Fig. 8 Sucrose concentration-response functions for regenerated single fiber (wavy lines) or fewfiber preparations (solid lines). The stage and age of regeneration are as follows: 55 , stage 5, 12 days; 70 and 74 , stage 4,15 days; 92 , stage 6,15 days; 98 , stage 5,15 days; and 103 , stage 3,13 days. The chorda tympani was crushed in gerbils $55,92,98$, and 103 , and transected in 70 and 74 . Ordinate as in figure 7 .

apparent diversity of fiber types, require a comparison with the response profiles of normal single chorda tympani fibers to evaluate the normalcy of regenerated fibers.

\section{E. Single fiber response profiles of} the normal chorda tympani nerve

From a population of 26 normal fibers we selected a random sample of seven units (fig. 6). The response profiles of normal single fibers were not qualitatively different from those of regenerated fibers. For example, $\mathrm{NH}_{4} \mathrm{Cl}$ was sometimes more effective than $\mathrm{NaCl}$ (12). Citric acid was more $(9,21)$ or less effective $(11,12)$ than acetic acid. Some units were principally salt sensitive (16), others principally responsive to sugars (11). On occasion a sweetener other than sucrose was the most effective (glycerol, 12). Owing to the inclusion of several units in an indeterminant number of the response profiles of regenerated nerves, it is not possible to make a direct quantitative comparison of either the absolute level of responding or of the spontaneous activity. However, it was clear that some regenerated single fibers gave more vigorous responses than some normal fibers. 


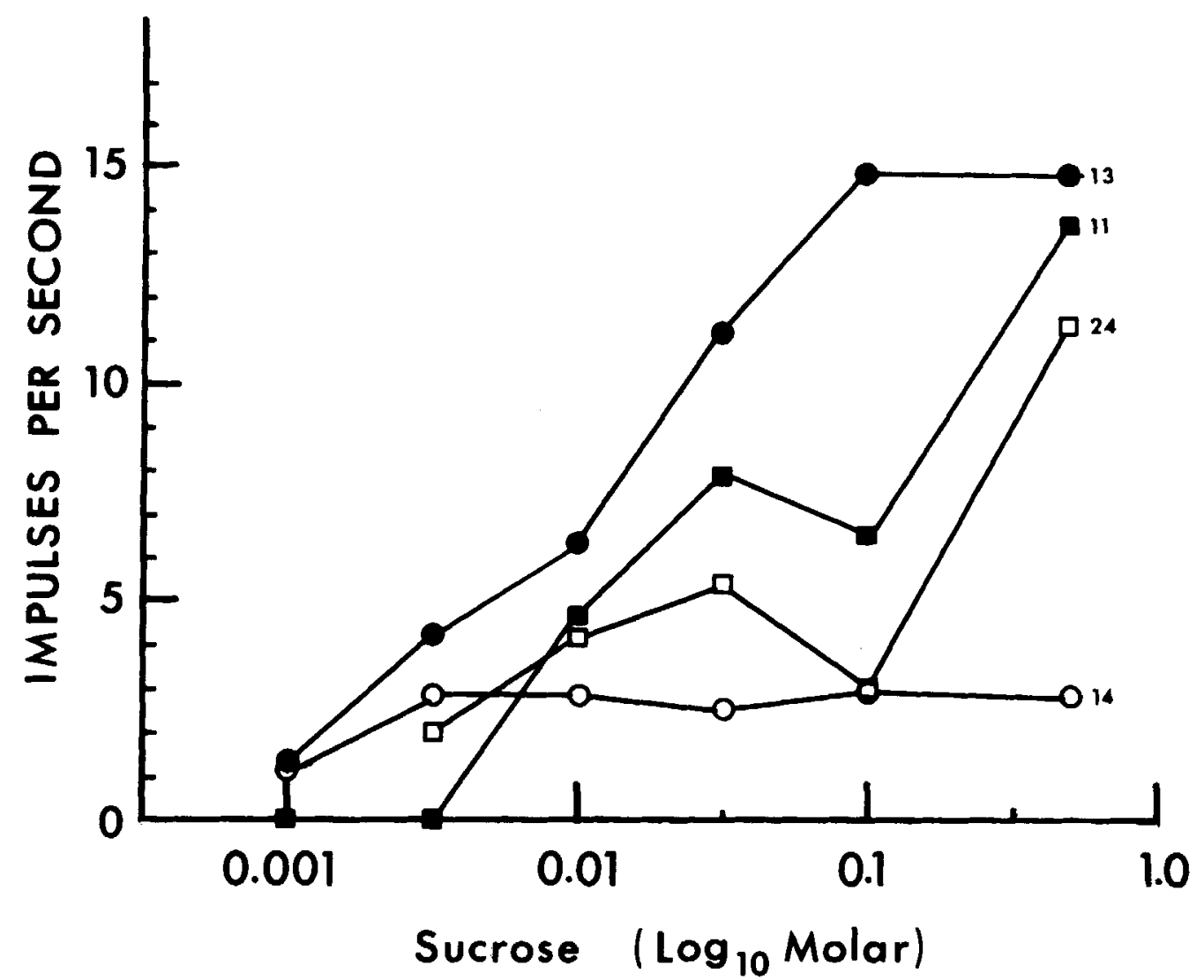

Fig. 9 Sucrose concentration-response functions for four normal single fibers. Ordinate as in figure 7.

\section{F. Concentration-response functions for $\mathrm{NaCl}$ and sucrose}

To examine in a more systematic manner how the regenerated fibers responded to concentration as a variable, several nerves were tested with a $\mathrm{NaCl}$ or sucrose concentration series applied to the tongue. These results are shown in figures 7 and 8 , where wavy lines indicate single fibers. The data indicate that the newly regenerated taste fibers increase their impulse output with increasing solution concentration. In four of six nerves a decline or dip in the impulse frequency occurred at some of the higher sucrose concentrations. We do not believe this resulted from inadequate rinsing between trials. We found a similar phenomenon in two of the four normal single fibers which we tested with a sucrose concentration series (fig. 9). We have insufficient data to determine whether the absolute threshold of the regenerating fibers was typically higher than the normal population of fibers.

\section{G. Receptive field properties}

In favorable circumstances it was possible to localize the receptive fields of some early functional taste units. Chemical stimuli were applied with a small paint brush. The most accurate localization was carried out with drops of $2.0 \mathrm{M}$ sucrose, which remained localized, whereas other chemicals tended to spread rapidly across the tongue surface. The important features of the localization tests are summarized in figure 

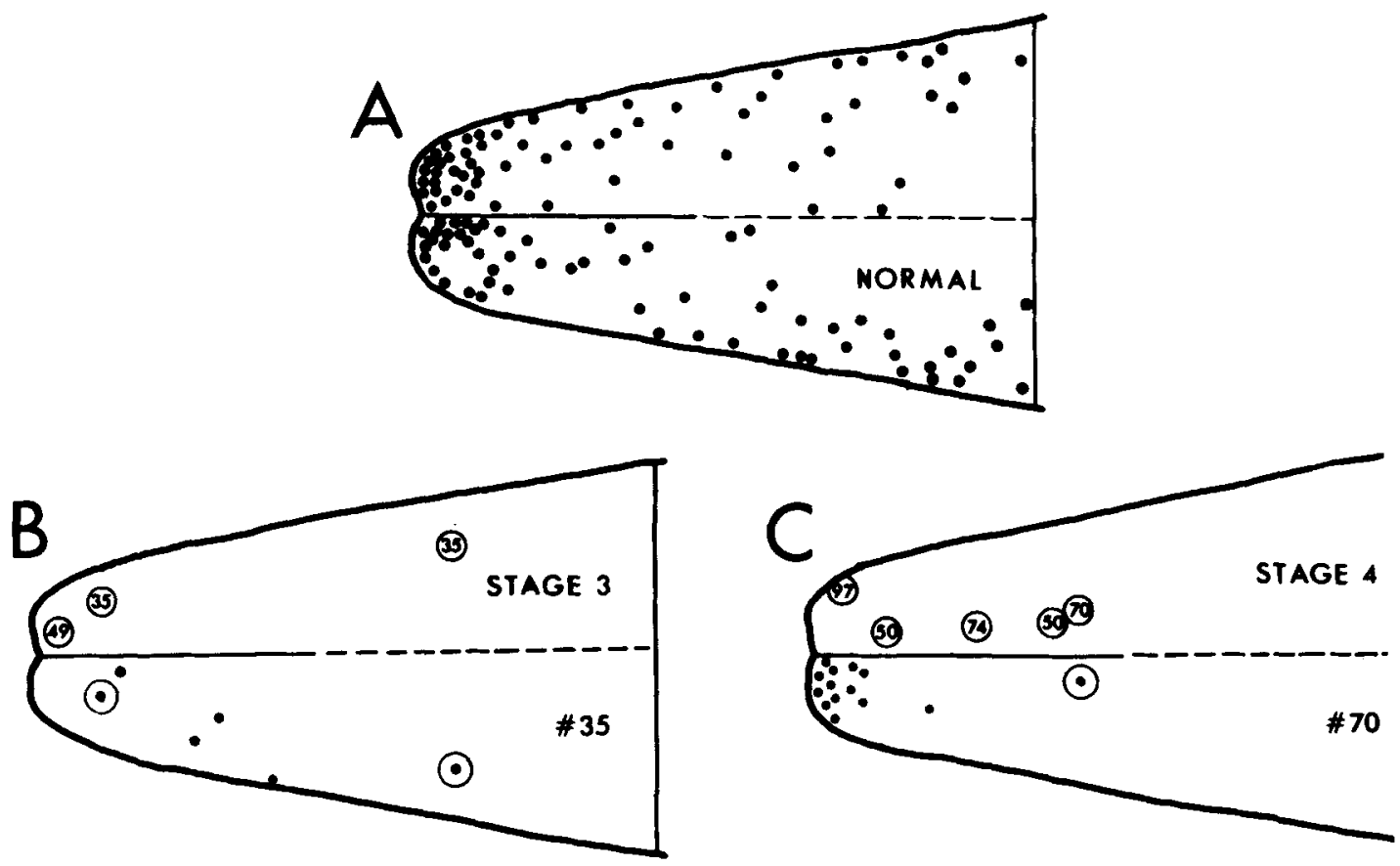

Fig. 10 Localization of taste receptive fields and taste buds in stage 3 and 4. A. Normal distribution of taste buds. The left and right sides of the tongue are from different animals. Reconstructed from serial cross-sections of the anterior $10 \mathrm{~mm}$ of iron hematoxylin stained tongues. B. Stage 3 of regeneration. The right side of the tongue shows loci of specific areas responsive to chemical stimuli (receptive field) for regenerated single fibers. Fiber 35 had two widely separated $(6 \mathrm{~mm})$ sub-regions of the receptive field which responded predominately to $\mathrm{NH}_{4} \mathrm{Cl}$. The response profile of fiber 35 is shown in figure 4. On the left side reconstructions from serial sections of the tongue of gerbil 35 show the location of its six regenerated fungiform taste buds. A circle has been placed around the two taste buds corresponding to the receptive field location of fiber 35. C. Stage 4 of regeneration. Right side shows receptive fields of four single or single-few fiber preparations. 50 has two separated sub-regions of the receptive field. The histologically determined location of the regenerated taste buds of 70 are shown on the left side. The specific taste bud within the receptive field is circled. This taste bud was innervated by unit 70 which responded predominately to sucrose (fig. 4).

10. The distribution of normal fungiform taste buds (left and right sides from different animals) is shown in figure 10A. The receptive fields were found on the ipsilateral side of the tongue for six gerbils in stages 3 and 4 (shown in the upper part of figs. 10B,C, respectively). 35,49 , and 70 were single fibers. 35 responded predominately to $\mathrm{NH}_{4} \mathrm{Cl}$ at two loci on the tongue; 49 to $\mathrm{NaCl}$, and a large unit in gerbil 70 to sucrose. Of the few-fiber preparations 50 responded best to $\mathrm{NaCl}$ and sucrose, 74 to glycine and sucrose and 97 to $\mathrm{NH}_{4} \mathrm{Cl}$ and $\mathrm{NaCl}$. Although the localization for 50,74 , and 97 was probably incomplete, it was evident that each fiber's receptive field was limited to a small num- ber of fungiform papillae. However, across animals responsiveness to a given chemical used in mapping (sucrose, $\mathrm{NaCl}, \mathrm{NH}_{4} \mathrm{Cl}$ ) did not appear to be restricted to a particular tongue region.

We assume that fibers which had been crushed had intact sheaths to help guide them without excessive exploratory branching to their normal papillae (Cheal and Oakley, '77). However, fibers which had been transected (70) did not necessarily undergo more terminal branching than crushed fibers (35).

It is interesting to note that in two gerbils we were able to show that two papillae associated with two different branches of the same axon had receptors with similar re- 
sponse profiles. Concordant receptors, as we term them, have been described previously for primary afferents in a study of the receptive fields of 20 chorda tympani fibers of the cat (Oakley, '75).

\section{H. Histological results}

A tongue of a given age or stage of functional recovery contained taste buds in various maturational states. Consequently, it was necessary to examine anatomically taste buds within the receptive field of a regenerating taste fiber. When receptive field localization was successful, at least one taste bud was present; although in several gerbils regenerating taste buds were sufficiently numerous that we could not determine with certainty which had been the functionally responsive taste buds. One taste bud was found within the receptive field of unit 70 (figs. 10C, 11B) and one within the posterior portion of the receptive field of unit 35 (figs. 10B, 11A). For each it must have been the functionally responsive taste bud, as no others were present in the region of the receptive field (figs. 10B, C). Both taste buds were modest in size and structural appearance. Some fusiform cells were present (arrow in figs. $11 \mathrm{~A}, \mathrm{~B}-3)$. Evidently a full complement of fusiform cells is unnecessary for mediation of functional responses.

\section{DISCUSSION}

The first taste responses could be recorded from the crushed chorda tympani nerve after a recovery period of 11 days. Since the regenerating axons were initially observed in fungiform papillae after eight days (Cheal and Oakley, '77) it required about three days for axons to reestablish a taste bud with functional receptors. Cutting the chorda tympani delayed this entire process by about two days, perhaps because complete transection was more traumatic or because the axons had greater mechanical difficulties in making their way to the fungiform papillae.

It is improbable that taste axons innervated residual fusiform taste receptor cells
(Cheal and Oakley, '77). The rapidity with which functional taste buds were reestablished sets temporal boundary conditions for the events which could be triggered by the axon's arrival in the fungiform papilla. We presume that in order for taste responses to occur there must be a taste pore providing access to the fusiform receptor cell's microvilli which contain molecular receptors for taste stimulants. In addition there must be a functional synapse with a chemical transmitter substance and post-synaptic receptors on the axon terminal. It seems feasible that such conditions could be established within the three days between the arrival of fibers and the presence of functional taste responses. The 3day period after axonal arrival would witness the differentiation of microvilli, the formation of properly located molecular receptors for taste, and the deposition of transmitter vesicles adjacent to the subsynaptic membrane. Microvilli could differentiate in a short period of time; the cells of the intestinal epithelium, which have microvilli, have an average lifespan of 60 hours (Quastler and Sherman, '59). During development vertebrate skeletal myotube membrane incorporates receptor molecules for acetylcholine at a rate of 35/ $\mathrm{hr} / \mu \mathrm{m}^{2}$ of cell surface (Hartzell and Fambrough, '73). This rate of synthesis seems adequate for accumulation of molecular receptors for taste substances in the smaller area of the taste receptor microvilli, even if these receptors are not synthesized until after the nerve arrives. The taste pore in the keratinized layer of the epithelium might be reformed or it might have survived the 11-day denervation period at least partially intact. The synaptic transmitter receptors in the post-synaptic membrane (axonal terminals) could have been readied before arrival at the fungiform papillae.

A primary concern of this study was to determine the response properties of young taste receptor cells. Experimentally interrupting the nerve (crushing) was designed to produce temporally coherent degeneration of taste buds followed by a wave of axonal reinnervation. The results 

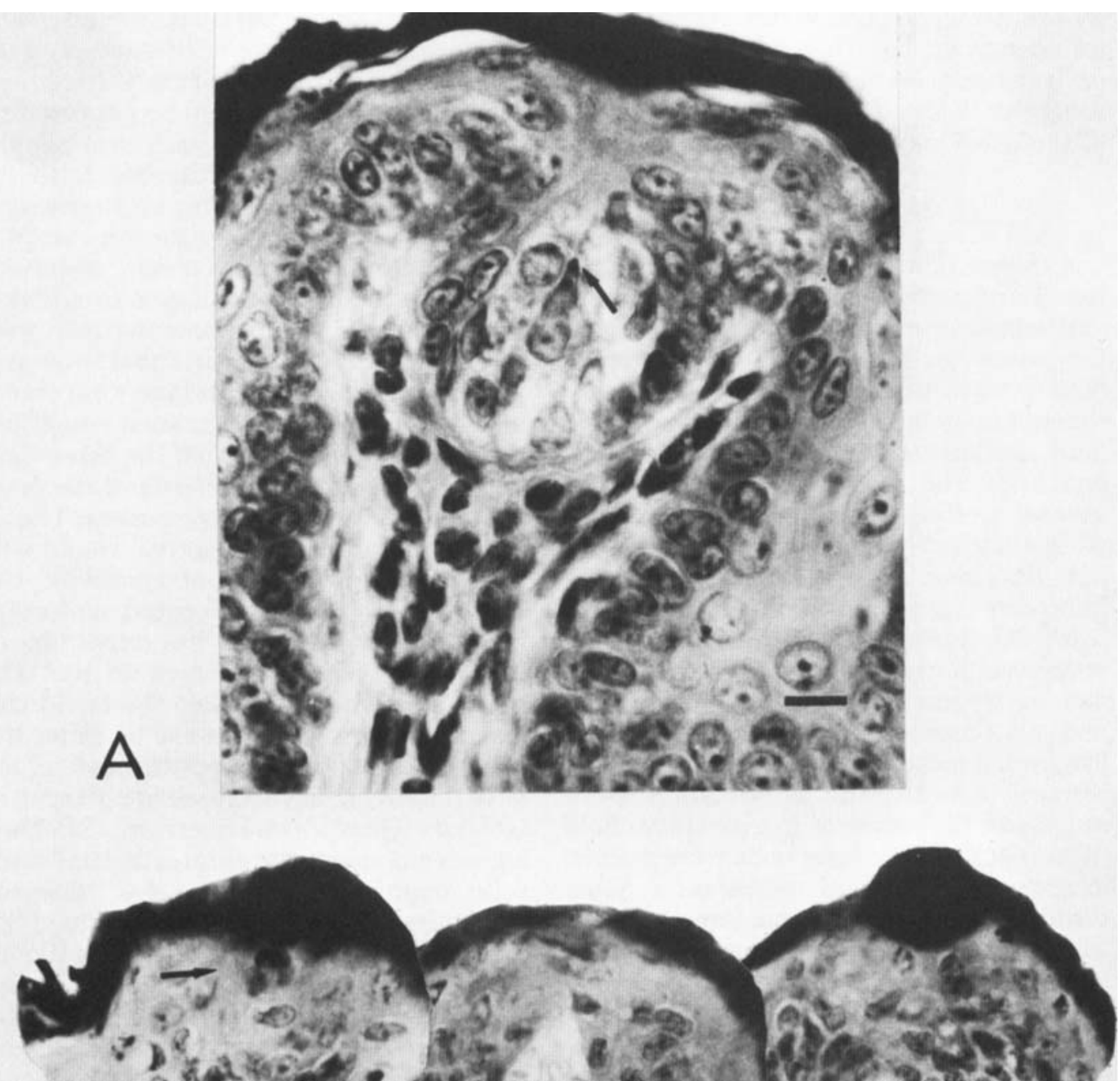

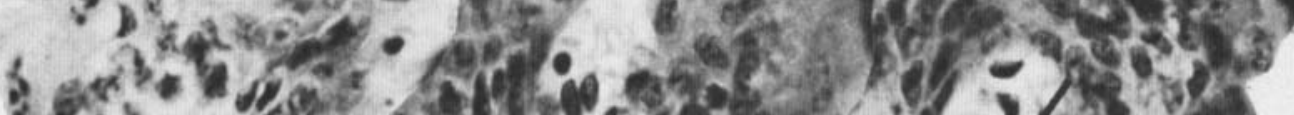

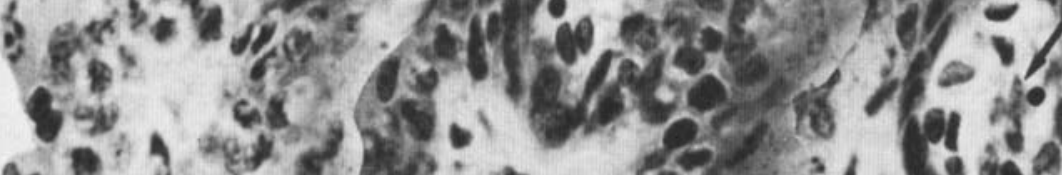
ce

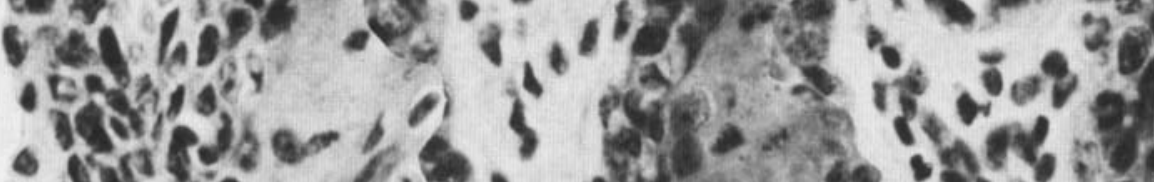

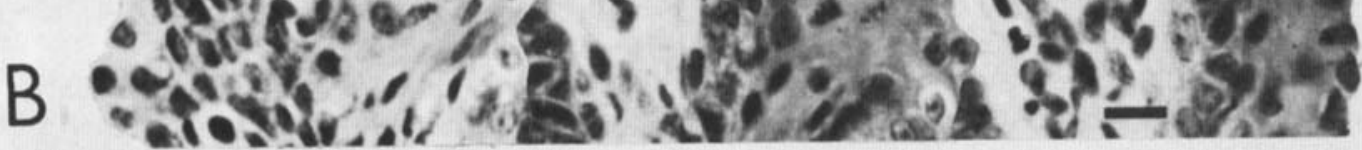

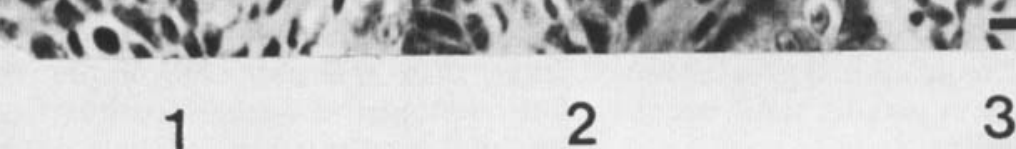


of axonal recording suggest that young receptor cells have normal responses.

Theoretically, it would appear that the functional regeneration of taste buds passes through an initial maturational phase, followed by phases of maturity and ageing. Since we monitored the recovery process with a time resolution of about one day we had anticipated at least a brief maturation phase during which the regenerated fibers might respond only to intense chemical stimulation or respond in an undifferentiated manner to structurally simple compounds or small ions. This was not the case. Normal responsivity and specificity appeared to be the rule both between and within classes of chemicals. Moderate concentrations were often effective (e.g., figs. 7, 8). Coupled with the observed presence of one or more taste buds within receptive fields, these results suggest that the responses were mediated by receptor cells with well differentiated molecular receptors for taste substances. Perhaps the establishment of a functional synapse is the last step to be accomplished in reinnervation. In two or three cases there were rather unresponsive taste fibers with high thresholds, but such fibers have also been encountered in normal preparations. In mature taste buds, cell turnover may cause the taste system to display some responses characteristic of maturation.

The only significant deviation from normal was the greater effectiveness of $\mathrm{NH}_{4} \mathrm{Cl}$ than $\mathrm{NaCl}$. Since this was a feature of the earliest period of regeneration and was not apparent at 15 days (fig. $3 \mathrm{C}$ ), we believe that this represents a maturational phase of

Fig. 11 Ten-micron hematoxylin stained sections of physiologically responsive taste buds. A. Section through the taste bud in the posterior part of the receptive field of unit 35 . See figure $10 \mathrm{~B}$ for the position of the bud on the tongue. The arrow points to a fusiform cell. Scale line, $10 \mu \mathrm{m}$. B. The taste bud in the receptive field of unit 70 . Because the sections were cut obliquely to the axis of the taste bud, three serial photomicrographs are shown. See figure $10 \mathrm{C}$ for the position of the taste bud on the tongue. The arrow in $B-1$ points to the faintly outlined narrow neck of the taste bud. The arrow in B-3 points to a fusiform cell. Scale line $10 \mu \mathrm{m}$. a regenerating system. It could be a result of the greater rapidity with which $\mathrm{NH}_{4} \mathrm{Cl}$ responsive axons or receptor cells regenerated, or represent other factors in maturation. Whatever the cause, it was not invarient; some early regenerated nerves displayed little responsiveness to $\mathrm{NH}_{4} \mathrm{Cl}$.

How are neural connections maintained with short-lived taste bud cells which migrate within the taste bud? Beidler and Smallman ('65) suggested that appropriate functional connections might be maintained if the response profile of a receptor cell changed over its lifespan. An axon at the perimeter of the bud would always contact young receptor cells (e.g., sucrose responsive cells) whereas fibers in the center of the bud would contact old receptor cells (e.g., quinine responsive cells). However, we found that instead of one type of response profile corresponding to young receptor cells, there was the normal diversity of response profiles and responsiveness to various chemicals. Had some of the receptors been residual old receptors, we would have expected to find only two types of response profiles. Instead we found, as determined by single and multi-unit recording, the normal variety of response properties. Profuse axonal branching within a fungiform taste bud (Beidler, '69) may give a receptor cell access to the endings of an axon regardless of the cell's position in the taste bud. Whether a synapse is then formed may depend on cell surface compatibility between an axonal ending and that particular cell (Oakley and Cheal, '75).

Our preliminary data on the structural substrate mediating taste responses suggests that a taste bud containing some fusiform cells is necessary. More data needs to be obtained on the topic of structural requirements.

The principle conclusions of this study are: (1) regenerating nerve fibers require about three days to reestablish a functional taste bud after reinnervating the fungiform papillae; (2) taste properties of young receptor cells and their axons were essentially normal; newly regenerated axons were not limited to a few response profiles. 


\section{ACKNOWLEDGEMENTS}

We are most grateful to I. Gross, L. Hewitt, S. Igras, and M. Mac for their dedicated assistance in various phases of this research. This work was supported in part by U. S. P. H. S. Grant N.S.-07072.

\section{LITERATURE CITED}

Baylor, D. A., and J. G. Nicholls 1968 Receptive fields, synaptic connections and regeneration patterns of sensory neurons in the CNS of the leech. In: Physiological and Biochemical Aspects of Nervous Integration. F. D. Carlson, ed. Prentice-Hall, Englewood Cliffs, New Jersey, pp. 3-16.

Beidler, L. M. 1969 Innervation of rat fungiform papilla. In: Olfaction and Taste. Proceedings of the Third International Symposium. C. Pfaffmann, ed. The Rockefeller Univ. Press, New York, pp. 352369.

Beidler, L. M., and R. L. Smallman 1965 Renewal of cells within taste buds. J. Cell. Biol., 27: 263-272.

Bradley, R. M., and C. M. Mistretta 1973 The gustatory sense in foetal sheep during the last third of gestation. J. Physiol., 231: 271-282.

1975 The developing sense of taste. In: Olfaction and Taste. V. Proceedings of the Fifth International Symposium. D. A. Denton and J. P. Coghlan, eds. Academic Press, New York, pp. 9198.

Brown, A. G., and A. Iggo 1963 The structure and function of cutaneous "touch corpuscles" after nerve crush. J. Physiol., 165: 28P-29P.

Burgess, P. R. , K. B. English, K. W. Horch and L. J.
Stensaas 1974 Patterning in the regeneration of type I cutaneous receptors. J. Physiol., 236: 57-82. Burgess, P. R., and K. W. Horch 1973 Specific regeneration of cutaneous fibers in the cat. J. Neurophysiol., 36: 101-114.

Cheal, M. L., and B. Oakley 1977 Regeneration of fungiform taste buds: temporal and spatial characteristics. J. Comp. Neur., 172: 609-626.

Guth, L. 1957 The effects of glossopharyngeal nerve transection on the circumvallate papilla of the rat. Anat. Rec., 128: 715-731.

Hartzell, H. C., and D. M. Farmbrough 1973 Acetylcholine receptor production and incorporation into membranes of developing muscle fibers. Dev. Biol., 30: 153-165.

Hellekant, G. 1971 Efferent impulses in the chorda tympani nerve of the rat. Acta Physiol. Scand., 83: 203-209.

Jakinovich, W., Jr., and B. Oakley 1975 Comparative gustatory responses in four species of gerbilline rodents. J. Comp. Physiol., 99: 89-101.

Oakley, B. 1967 Altered temperature and taste responses from cross-regenerated sensory nerves in the rat's tongue. J. Physiol., 188: 353-371.

- 1975 Receptive fields of cat taste fibers. Chem. Senses and Flavor, 1: 431-442.

Oakley, B., and M. L. Cheal 1975 Regenerative phenomena and the problem of taste ontogenesis. In: Olfaction and Taste. V. Proceedings of the Fifth International Symposium. D. D. A. Denton, and J. P. Coghlan, eds. Academic Press, New York, pp. 99105.

Quastler, H., and F. G. Sherman 1959 Cell population kinetics in the intestinal epithelium of the mouse. Exp. Cell Research, 17: 420-424. 